\title{
Electronic structure and spectroscopic properties of copper catecholate complexes with interligand charge-transfer behavior
}

\author{
Roland Benedix* \\ Wissenschaftsbereich Chemie, Hochschule für Technik, Pf 66, 0-7030 Leipzig (Germany) \\ and Arnd Vogler \\ Institut für Anorganische Chemie, Universität Regensburg, Universitätsstrasse 31, W-8400 Regenshurg (Germany)
}

(Received August 21, 1992)

\begin{abstract}
The structural and spectroscopic properties of copper catecholatc complexes with nitrogen ligands of the $\alpha$ diimine type are studied by qualitative MO considerations. The characteristic feature of these donor acceptor systems is an interligand charge-transfer from the catecholate donor to the $\alpha$-diimine acceptor site. The dependence of the interligand charge-transfer absorption band on the energies of the acceptor and the donor levels as well as on the solvent polarity is discussed.
\end{abstract}

\section{Introduction}

In recent years mixed-ligand complexes with an electron-rich, more readily oxidizable donor ligand (e.g. dithiolates, catecholates, diselenolates) and a bidentate acceptor ligand with energetically low-lying empty orbitals (e.g. $\alpha$-diimines) have been the subject of numerous studies [1-15]. These compounds are characterized by intense interligand charge-transfer (LL'CT) absorptions in the visible region.

The first compounds of this type were investigated by Miller and Dance [1]. They detected LL'CT bands in the spectra of square-planar nickel compounds of dithiolate and $\alpha$-diimine ligands of the general formula $[\mathrm{Ni}(\mathrm{S}, \mathrm{S}) \mathrm{N}, \mathrm{N}]$. Thereafter, many further examples of such donor acceptor systems with S,S-, S,O-, O,O- and $\mathrm{Se}, \mathrm{Se}$-donor and $\mathrm{N}, \mathrm{N}$-acceptor ligands with various $\mathrm{d}^{8}$ metals have been discovered [3-5, 7-11]. Koester assigned a spectral band in the visible region of [ $\mathrm{Zn}$ (dithiolate) $\alpha$-diimine] complexes also to an $\mathrm{S}, \mathrm{S} \rightarrow \mathrm{N}, \mathrm{N}$ interligand $\mathrm{CT}$ transition [2]. Based on absorption and luminescence investigations as well as MO calculations we have shown that the electron delocalization between both ligands in the $[\mathrm{Zn}(\mathrm{S}, \mathrm{S}) \mathrm{N}, \mathrm{N}]$ system, and hence the degree of charge separation which is associated with $L L^{\prime} C T$, depends strongly on the torsion angle which is formed by the planes of both ligands [14]. Recently, Lever and co-workcrs described octa-

*Author to whom correspondence should be addressed. hedral ruthenium mixed-ligand complexes with donor ligands of the catecholate (cat) and semiquinone (sq) type and 2,2'-bipyridine (bipy) as acceptor ligand [12, 13]. Besides MLCT $\operatorname{Ru}(\mathrm{d} \pi) \rightarrow \pi^{*}$ (bipy) bands LL'CT cat/sq $\rightarrow$ bipy absorptions were detected in the visible region above $500 \mathrm{~nm}$. These results agree with our conclusions on the zinc system [14]. A planar arrangement of the interacting $\pi$ systems is apparently not a necessary condition for effective interligand CT interactions.

While various combinations of donor and acceptor ligands in different geometries have been investigated systematic studies of the influence of the metal on the LL'CT effect have not yet been carried out [15]. In order to extend our knowledge on these compounds we describe here the interligand CT behavior of copper(II) complexes.

The synthesis of a series of ternary copper catecholate chelates with bidentate nitrogen counter ligands was first reported by Brown et al. in 1976 [16]. These authors observed a rather intense visible absorption in the region between 420 and $540 \mathrm{~nm}\left(\epsilon \approx 2 \times 10^{3} \mathrm{l} \mathrm{mol}^{-1}\right.$ $\mathrm{cm}^{-1}$ ) but made no assignment. In a later study this band was attributed to a copper $\rightarrow$ catecholate $\left(\pi^{*}\right)$ MLCT transition [17]. However, since $\mathrm{Cu}(\mathrm{II})$ is hardly reducing MLCT transitions of $\mathrm{Cu}$ (II) complexes are not expected to occur at energies smaller than 20000 $\mathrm{cm}^{-1}$. In order to understand the optical properties of this mixed-ligand system we synthesized and characterized a variety of copper complexes with catecholates 
and $\alpha$-diimines as ligands. On the basis of MO calculations an analysis of the electronic spectra of thesc compounds is presented.

\section{Experimental and calculational details}

Catechol, 3,5-di-tert-butylcatechol, 2,2'-bipyridine and 1,10-phenanthroline (Aldrich) were used as supplied. The aliphatic diimine ligands were synthesized according to published procedures [18-20]. Other chemicals used were of analytical reagent grade. The copper catecholate $\alpha$-diimine complexes were prepared as described by Brown et al. [16].

Electronic absorption spectra were recorded on a Cary 3, Varian. Spectro-grade solvents were used for spectroscopic measurements.

All calculations were performed in the framework of the extended-Hückel LCAO method $[21,22]$. In the calculations the so-called 'weighted $H_{i j}$ formula' for the off-diagonal elements $\left(H_{i j}\right)$, which is a modified Wolfsberg-Helmholz formula, was used in order to take into account the phenomenon of counterintuitive orbitalmixing common in calculations of transition-metal complexes [23].

Single Slater-type orbitals were used for the main group elements and for the $s$ and $p$ functions of the metal, while the $\mathrm{d}$ wave functions were taken as a contracted linear combination of two Slater-type functions published by Richardson et al. [24].

The bond lengths and angles of the complexes are taken from X-ray crystallographic data [25-29]. The internal coordinates used for the $\alpha$-diimines are given in refs. 30 and 31 .

In the text and tables, abbreviations are explained as follows: cat $=$ catecholate; dbcat $=3,5$-di-tert-butylcatecholate; $\mathrm{Cl}_{4}$ cat $=$ tetrachlorocatecholate; ox $=$ oxalate; $p y=$ pyridine; bipy $=2,2^{\prime}$-bipyridine; phen $=1,10$ phenanthroline; gmi $=N, N^{\prime}$-dimethylglyoxal diimine; $\mathrm{dda}=N, N^{\prime}$-diphenyldiacetyl diimine, paa = pyridine-2aldehyde- $N$-phenylimine; bda $=N, N^{\prime}$-diphenylbenzil diimine.

\section{Results and discussion}

Five mixed-ligand complexes of the general formula $[\mathrm{Cu}$ (cat) $\alpha$-diimine] were prepared and characterized by metal analysis and magnetic measurements (Table 1). In accordance with XPS data reported by Brown et al. [17] the magnetic moments confirm the presence of $\mathrm{Cu}(\mathrm{II})$. The ESR parameters are also consistent with copper(II). The $g$ valucs of the polycrystalline samples lie in the range $2.04-2.20$, e.g.
TABLE 1. Metal analysis, magnetic moments and absorption maxima of $[\mathrm{Cu}(\mathrm{cat}) \mathrm{N}, \mathrm{N}]$ complexes

\begin{tabular}{lllll}
\hline N,N & Copper $(\%)$ & & $\begin{array}{l}\mu_{\text {eff }} \\
(B M)^{\mathbf{a}}\end{array}$ & $\begin{array}{l}\text { LL'CT } \\
(\mathrm{nm})^{\mathbf{b}}\end{array}$ \\
\cline { 2 - 3 } & Found & Calc. & & \\
\hline bipy & 19.12 & 19.4 & 1.78 & 480 \\
phen & 17.83 & 18.06 & 1.9 & 490 \\
paa & 18.15 & 17.96 & 1.82 & 510 \\
dda & 15.33 & 15.58 & 1.76 & 555 \\
hda & 12.16 & 11.94 & 1.92 & 612 \\
\hline
\end{tabular}

a298 K. bIn DMSO.

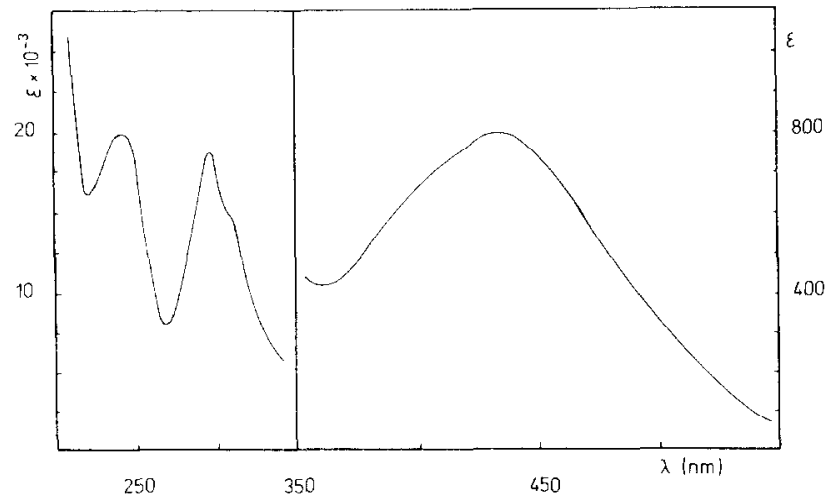

Fig. 1. Electronic spectrum for [Cu(cat)bipy] in $\mathrm{CH}_{3} \mathrm{OH}, 298 \mathrm{~K}$.

$$
\begin{aligned}
& {[\mathrm{Cu} \text { (cat)bipy }]} \\
& g_{\perp}=2.054 \pm 0.003, g_{\|}=2.190 \pm 0.003 \\
& {[\mathrm{Cu} \text { (cat)dda }]} \\
& g_{\perp}=2.047 \pm 0.003, g_{\|}=2.162 \pm 0.003
\end{aligned}
$$

The solid compounds contain magnetically dilute copper(II) complexes having no strong copper-copper interaction. The complexes may thus be considered as monomeric copper(II) species with approximately square-planar geometry [32]. This assumption is supported by the observation that the ESR spectra yield lowest $g$ values larger than 2.04 which are consistent with a $\mathrm{d}_{x y}$ or a $\mathrm{d}_{x^{2}-y^{2}}$ ground state.

All mixed-ligand copper complexes under study show a similar pattern of their electronic spectra. As a typical example the absorption spectrum of [Cu(cat)bipy] is shown in Fig. 1. The position of the characteristic longwavelength band of all complexes is given in Table 1 . The absorption bands in the visible region have an intensity of approximately $\epsilon=10^{3} 1 \mathrm{~mol}^{-1} \mathrm{~cm}^{-1}$. More accurate measurements were hampered by the low solubility of these compounds and their air sensitivity in solution. In particular, the dbcat complexes undergo a facile oxidation by $\mathrm{O}_{2}$.

The two principal absorptions in the UV region at $\lambda=220-350 \mathrm{~nm}$ (Fig. 1) can be assigned to intraligand 
transitions of the diimine ligands. The catecholate intraligand bands which are expected to occur also in this region of the spectrum are apparently obscured by the diimine bands [17].

The long-wavelength region of the absorption spectra is dominated by the characteristic band located between 430 and $550 \mathrm{~nm}$ (Fig. 1, Table 1). Brown et al. attributed this band to the presence of the catecholate ligand since it is absent in the spectra of diimine complexes such as $\left[\mathrm{Cu}\right.$ (phen) $\left.\mathrm{Cl}_{2}\right]$. However, homoleptic catecholate complexes such as $\left[\mathrm{Cu}(\mathrm{dbcat})_{2}\right]^{2-}$ [33] also do not display the typical long-wavelength absorption of the mixedligand $[\mathrm{Cu}(\mathrm{O}, \mathrm{O}) \mathrm{N}, \mathrm{N}]$ complexes. It follows that this band must have another origin.

Based on the position and high intensity of this absorption a ligand-field transition can be excluded. Generally, dd bands of $\mathrm{Cu}$ (II) complexes appear in the region $500-700 \mathrm{~nm}$ with an intensity of the order of $10^{2} 1 \mathrm{~mol}^{-1} \mathrm{~cm}^{-1}$ [34]. The assignment of the longwavelength band of the $[\mathrm{Cu}(\mathrm{O}, \mathrm{O}) \mathrm{N}, \mathrm{N}]$ complexes to a $\mathrm{Cu}(\mathrm{II}) \rightarrow$ diimine MLCT transition is also not appropriate. While $\mathrm{Cu}(\mathrm{I})$ diimine complexes show indeed such MLCT absorptions at low energies [35, 36], Cu(II) is much less reducing than $\mathrm{Cu}(\mathrm{I})$.

It is apparent that the presence of both types of ligands, the catecholate and the $\alpha$-diimine, is a necessary condition for the appearance of the visible bands of the $[\mathrm{Cu}(\mathrm{O}, \mathrm{O}) \mathrm{N}, \mathrm{N}]$ complexes. In agreement with previous studies on related systems [1-15] and as a logical conclusion we assign this dominant long-wavelength absorption to an interligand charge-transfer (LL'CT) transition from the catecholate donor to the diimine acceptor ligand. The IL.'CT interaction of both ligands is supported and elaborated by further observations and considerations.

The LL'CT band is shifted to longer wavelengths when the $\pi$ acceptor ability of the diimine ligand is increased. The order reported in Table 1 agrees with independent experimental and theoretical data on diimine ligands [30]. In particular, the lower energy of the $\pi^{*}$ LUMO of aliphatic diimines (dda, bda) compared to that of aromatic diimines (bipy, phen) is in accord with our results.

The position of an interligand CT band should also depend on the energy of the donor level. This expectation is indeed confirmed for the complexes $[\mathrm{Cu}(\mathrm{O}, \mathrm{O})$ bipy] with $\mathrm{O}, \mathrm{O}=\mathrm{dbcat}(\lambda=530 \mathrm{~nm})$, cat $(480$ $\mathrm{nm})$ and $\mathrm{Cl}_{4}$ cat $(420 \mathrm{~nm})$ [16]. In this order the hypsochromic shift of the band arises from a stepwise stabilization of the donor HOMO. This observation adds further evidence to the assumption that the catecholate ligand and not the metal acts as the donor within the CT transition.

A dominant feature of the interligand $\mathrm{CT}$ band of planar $\mathrm{d}^{8}$ complexes is its remarkable solvent sensitivity.
The $[\mathrm{Cu}(\mathrm{O}, \mathrm{O}) \mathrm{N}, \mathrm{N}]$ complexes also show a strong negative solvatochromism. The blue shift of the LL'CT band with increasing solvent polarity suggests a polarized ground state that can be stabilized by polar solvents. In the excited state the dipole moment is apparently reduced and polar solvents do not stabilize the excited state to the same extent. The application of Reichardt's $E_{\mathrm{T}}$ parameter [37] for solvent polarity yields a linear correlation between the energy of the LL'CT band and the $E_{\mathrm{T}}$ values (Fig. 2). Owing to the low solubility of the complexes only a limited number of solvents could be used. It is quite interesting that this solvatochromism is rather independent of the donor ligand. When in $[\mathrm{Cu}(\mathrm{O}, \mathrm{O})$ bipy] the ligand cat is replaced by dbcat the red shift of the LL'CT band of about $50-80 \mathrm{~nm}$ is preserved in different solvents, e.g. from 480 to 530 $\mathrm{nm}$ in DMSO, 433 to $501 \mathrm{~nm}$ in n-propanol and 435 to $501 \mathrm{~nm}$ in DMF.

The conclusions on the interligand donor acceptor interaction which are based on the experimental data are confirmed and supported by theoretical considerations. The MO diagram of [Cu(cat)bipy] calculated by the EHT method is shown in Fig. 3. Hydrogen atoms are omitted in the orbital representation for the sake of clarity, the symmetry labels are taken from the $C_{2 v}$ point group.

In agreement with SCF- $\mathrm{X}_{\alpha}$ calculations of Maroney et al. [38] on square-planar $\mathrm{CuN}_{2} \mathrm{O}_{2}$ complexes the highest singly occupied $\mathrm{MO}\left(2 \mathrm{~b}_{2}\right)$ has a relatively large metal contribution $\left(\mathrm{d}_{x y}: 78 \%\right)$ with a small contribution of $\mathrm{N}\left(\mathrm{p}_{\sigma}\right)$ orbitals. Below the HOMO mainly $\pi$ bonding of the cat and of the $\alpha$-diimine ligand are located. At lower energies $(\approx 13.5 \mathrm{eV})$ follows the $\mathrm{d}$ block. The further $\pi$ and $\sigma$ orbitals at still lower energy are not shown in Fig. 3.

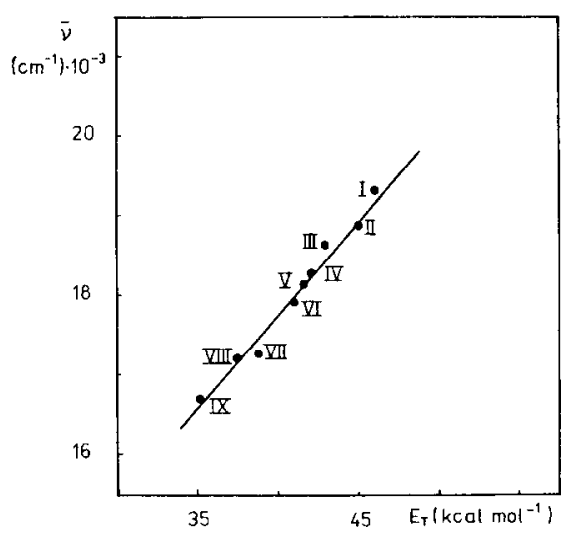

Fig. 2. Dependence of the wavenumber for the interligand chargetransfer band of [Cu(dbcat)bipy] on the solvent parameter $E_{\mathrm{T}}$ : I, acetonitrile; II, dimethyl sulfoxide; III, dimethylformamide; IV, acetone; V, nitrobenzene; VI, dichloromethane; VII, chloroform; VIII, tetrahydrofuran; XI, $o$-xylene. 


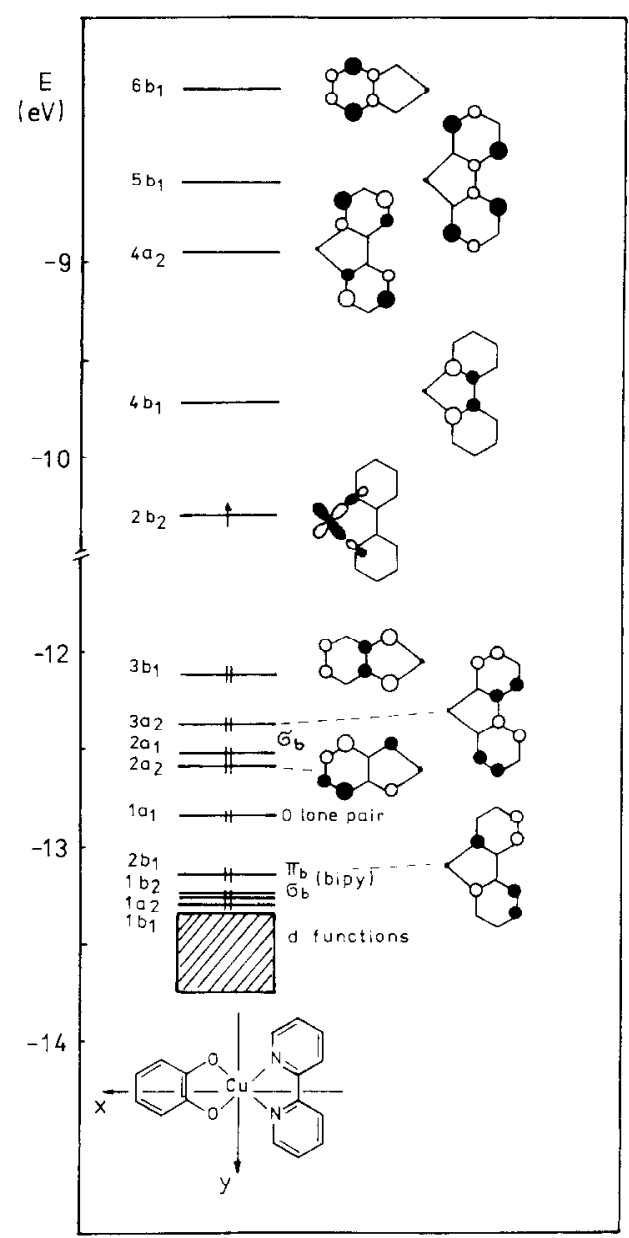

Fig. 3. Molecular orbital diagram of [Cu(cat)bipy]; the symmetry labels are taken from $C_{2 v}$ point group.

As expected, the lowest unoccupied MO $\left(4 b_{1}, \pi\right)$ is mainly localized on the diimine with the typical symmetry properties of the butadienoid $\chi_{3}$ orbital. At higher energies $\mathrm{CN}$ - and $\mathrm{CC}-\pi$ antibonding MOs of the diimine ligand are arranged followed by the lowest antibonding $\operatorname{cat}\left(6 \mathrm{~b}_{1}, \pi\right)$ MO at about $-8 \mathrm{eV}$.

Based on this scheme the longest-wavelength absorption can be assigned to an allowed $x$-polarized $3 \mathrm{~b}_{1} \rightarrow 4 \mathrm{~b}_{1}$ transition of the interligand $C T$ type (cat $\rightarrow$ bipy). The calculated energy difference $\Delta E=2.36$ eV $\left(19035 \mathrm{~cm}^{-1}\right)$ agrees surprisingly well with the experimental band energy of $\bar{\nu}=20835 \mathrm{~cm}^{-1}$. The shoulder at the short-wavelength side of the visible band at $500 \mathrm{~nm}$ may be caused by the second allowed $y$-polarized LL'CT transition $2 \mathrm{a}_{2} \rightarrow 4 \mathrm{~b}_{1}$ with $\Delta E=2.86$ eV $\left(23070 \mathrm{~cm}^{-1}\right)$. The $3 b_{1}($ cat $) \rightarrow 2 b_{2}\left(\mathrm{Cu}, \mathrm{d}_{x y}\right) / \mathrm{LMCT}$ and $2 b_{2}\left(\mathrm{Cu}, \mathrm{d}_{x y}\right) \rightarrow 4 \mathrm{~b}_{1}$ (diimine)/MLCT transitions are symmetry forbidden.

As described above, planar copper complexes exhibit a broad structured ligand-field band that can be attributed to the electronic transitions $x^{2}-y^{2} \rightarrow x y$, $z^{2} \rightarrow x y$. In the complexes of the type $\mathrm{CuN}_{2} \mathrm{O}_{2}$ the band appears in the range $\lambda=610-650 \mathrm{~nm}$ [34]. The calculated energy difference between the $2 b_{2}(x y)$ orbital and the $\mathrm{d}$ block is somewhat too large indicating an overestimation of the destabilization of the $x y$ function within the EHT formalism. LF bands were not detected in the spectrum of $[\mathrm{Cu}(\mathrm{O}, \mathrm{O}) \mathrm{N}, \mathrm{N}]$ but should be obscured by the long-wavelength side of the interligand $C T$ band.

Interestingly, an interligand charge-transfer band in the visible spectrum of the related [Cu(ox)bipy] system has not been observed [39, 40]. In Fig. 4 the MO diagrams of the complexes [Cu(cat)N,N] and $[\mathrm{Cu}(\mathrm{ox}) \mathrm{N}, \mathrm{N}]$ with $\mathrm{N}, \mathrm{N}=\mathrm{gmi}$ are shown. The $a_{2}$ (cat) $\rightarrow 2 b_{1}$ and especially the $x$-polarized $b_{1}$ (cat) $\rightarrow 2 b_{1}$ donor to acceptor transitions, responsible for the intense CT band are shifted to higher energies in the oxalate complex (the corresponding oxalate donor orbitals are located at about $-14.8 \mathrm{eV}$ ). The LL'CT bands are thus expected to occur in the UV region of the electronic spectrum.

In summary, the present study represents a significant extension of the class of ligand donor acceptor systems. The copper mixed-ligand complexes with a catecholate as donor and an acceptor ligand with energetically lowlying empty orbitals are characterized by intense visible bands of the interligand charge-transfer type. Their electronic structure is quite similar to that of the welldescribed planar $\mathrm{d}^{8}$ mixed-ligand complexes of the general formulas $[\mathrm{M}(\mathrm{O}, \mathrm{O}) \mathrm{N}, \mathrm{N}],[\mathrm{M}(\mathrm{S}, \mathrm{S}) \mathrm{N}, \mathrm{N}]$ and $[\mathrm{M}(\mathrm{Se}, \mathrm{Se}) \mathrm{N}, \mathrm{N}]$, with strong localized MOs in the frontier orbital region.

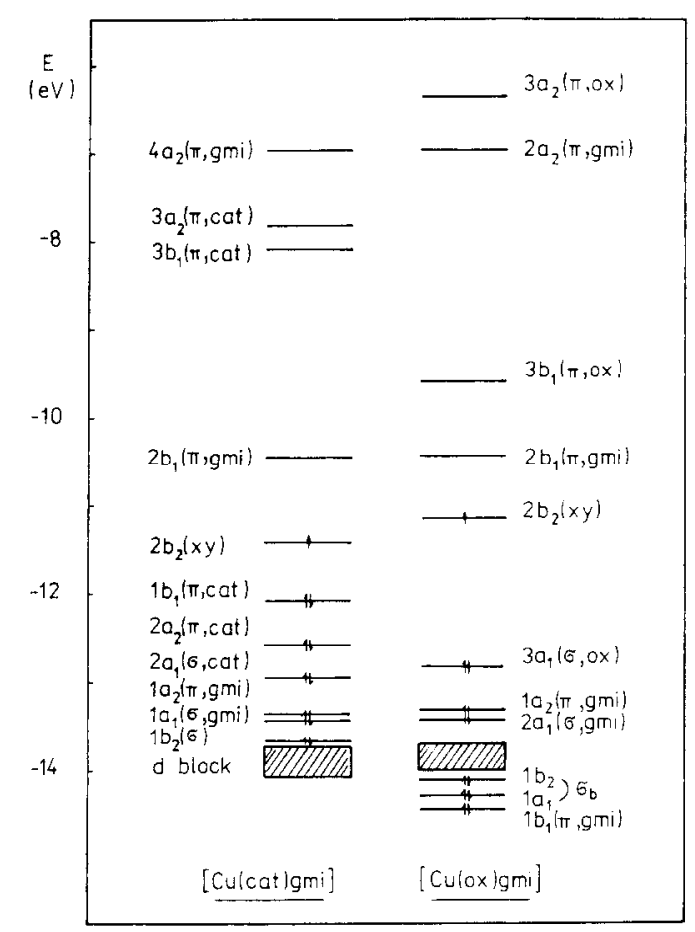

Fig. 4. Molecular orbital diagrams of $[\mathrm{Cu}(\mathrm{ox}) \mathrm{gmi}]$ and [Cu(cat)gmi]. 


\section{Acknowledgements}

We are grateful to D. Rehorek for EPR measurements. Financial support for this research by the Deutsche Forschungsgemeinschaft is gratefully acknowledged.

\section{References}

1 T. J. Miller and I. G. Dance, J. Am. Chem. Soc., 95 (1973) 6970.

2 V. J. Koester, Chem. Phys. Lett., 32 (1975) 575.

3 A. Vogler and H. Kunkely, J. Am. Chem. Soc., 103 (1981) 15.59.

4 A. Vogler, H. Kunkely, J. Hlavatsch and A. Merz, Inorg. Chem., 23 (1984) 506.

5 L. Kumar, K. H. Puthraya and T. S. Srivastava, Invry. Chim. Acta, 86 (1984) 173.

6 G. A. Heath, L. J. Yellowlees and P. S. Bratermann, Chem. Phys. Lett., 92 (1982) 646.

7 R. Benedix, D. Pitsch, K. Schöne and H. Hennig, Z. Anorg. Allg. Chem., 542 (1986) 102.

8 R. Benedix and H. Hennig, Inorg. Chim. Acta, 141 (1988) 21.

9 G.-E. Matsubayashi, M. Hirao and T. Tanaka, Inorg. Chim. Acta, 144 (1988) 217.

10 S. S. Kamath, V. Uma and T. Srivastava, Inorg. Chim. Acta, $166(1989) 91$.

11 G.-E. Matsubayashi and Y. Hiroshige, Inorg. Chim. Acta, 183 (1991) 173.

12 M. Haga, E. S. Dodsworth and A. B. P. Lever, Inorg. Chem., 25 (1986) 447.

13 H. Masui, A. B. P. Lever and P. R. Auburn, Inorg. Chem., 30 (1991) 2402.

14 R. Benedix, H. Hennig, H. Kunkely and $\Lambda$. Vogler, Chem. Phys. Lett., 175 (1990) 483.

15 A. Vogler and H. Kunkely, Comments Inorg. Chem., 9 (1990) 201.

16 D. G. Brown, J. T. Reinprecht and G. C. Vogel, Inorg. Nucl. Chem. Lett., 12 (1976) 399.

17 D. G. Brown, W. J. Hughes and G. Knerr, Inorg. Chim. Acta, 46 (1980) 123.
18 H.tom Dieck and J. W. Renk, Chem. Ber., 104 (1971) 92, 110; 105 (1972) 1403, 1419.

19 J. M. Kliegmann and R. K. Barnes, J. Org. Chem., 35 (1970) 3140.

20 G. Bähr and H. Thämlitz, Z. Anorg. Allg. Chem., 282 (1955) 8.

21 R. Hoffmann, J. Chem. Phys., 39 (1963) 1397.

22 C. J. Ballhausen and H. B. Gray, Molecular Orbital Theory, W. A. Benjamin, New York, 1965.

23 J. H. Ammeter, H. B. Bürgi, J. C. Thibeault and R. Hoffmann, J. Am. Chem. Soc., 100 (1978) 3686.

24 J. W. Richardson, W. C. Nieuwpoort, R. Powell and W. F. Edgel, J. Chem. Phys., 36 (1962) 1057.

25 C. G. Pierpoint and R. M. Buchanan, Coord. Chem. Rev., 38 (1981) 45.

26 W. Fitzgerald, J. Fooley, D. McSweeney, N. Ray, D. Sheanon, S. Tyagi, B. Hathaway and P. O'Brien, J. Chem. Soc., Dalton Trans., (1982) 1117.

27 M. Julve, J. Faus, M. Verdauguer and A. Gleizes, J. Am. Chem. Soc., 106 (1984) 8306.

28 I. Castro, J. Faus, M. Julve, M. C. Munoz, W. Diaz and X. Solans, Inorg. Chim. Acta, 179 (1991) 59.

29 A. Fabretti, G. Franchini, P. Zannini and M. Divara, Inorg. Chim. Acta, 105 (1985) 187.

30 J. Reinhold, R. Benedix, P. Birner and H. Hennig, Inorg. Chim. Acta, 33 (1979) 209.

31 M. Blandamer, J. Burgess, J. Fawcett, P. Guardado, C. D. Hubbard, S. Nuttall, L. J. S. Prouse, S. Radulovic and D. R. Russell, Inorg. Chem., 31 (1992) 1383.

32 B. J. Hathaway, Struct. Bonding (Berlin), 57 (1984) 55.

33 S. I Iarmalkcr, S. E. Jones and D. T. Sawyer, Inorg. Chem., 22 (1983) 2790.

34 A. B. P. Lever, Inorganic Electronic Spectroscopy, Elsevier, Amsterdam, 1984.

35 D. J. Casadonte, Jr. and D. R. McMillin, J. Am. Chem. Soc., 109 (1987) 331.

36 A. K. Ichinaga, J. R. Kirchoff, D. R. McMillin, C. O. DietrichBuchecker, P. A. Marnot and J.-P. Sauvage, Inorg. Chem., 26 (1987) 4290.

37 C. Reichardt, Solvent Effects in Organic Chemistry, Verlag Chemie, Weinheim, 1979.

38 M. J. Maroney, J. G. Norman, Jr. and J. H. Osborne, Inorg. Chem., 23 (1984) 2261.

39 F. A. Walker, H. Sigel and D. B. McCormick, Inorg. Chem., 11 (1972) 2756.

40 P. O'Brien, J. Chem. Soc., Dalton Trans. (1981) 1540. 